\title{
E-Participation in the Philippines: A Capabilities Approach to Socially Inclusive Governance
}

\author{
Benjamin D Huffman
}

T466-0823, Furocho, Chikusa Ward, Nagoya, Aichi Prefecture, Nagoya University, Graduate School of International Development, kwakjamin@hotmail.com

\begin{abstract}
Information and Communication Technologies have the potential to transform the political landscape by engaging citizens in the governance process. Whether citizens find value in utilizing these technologies is contentious. This article examines the capabilities affecting citizen's opportunities to achieve value through e-Participation in order to establish a framework that can foster these conditions. Previous e-Participation models have failed to capture this quintessence ideal, instead opting to take an access based approach to socially inclusive governance. The Philippines was selected for investigation based on its aggressive push to improve information and communication infrastructure, e-Government services and most notably, e-Participation. The main findings of this article show that Web 2.0 technologies such as Facebook have proven to be strong civic technologies for fostering e-Democracy but the government's effort to deepen democracy through e-Participation has yet to materialize into value to the common citizen. This is due to inadequately written policies and paper freedoms not translating into real ones. This article breaks way from the traditional access based model for e-Participation by presenting a normative framework which draws on the existential capabilities of citizens. Cultivating e-Participation in such a way can empower citizens and strengthen the state through a deepening of democracy.
\end{abstract}

Keywords: E-Participation, Web 2.0, E-Governance, E-Democracy, Capability Approach

Acknowledgement: A summarized version of this article was previously submitted to the CeDEM Asia 2016 conference. The author would like to express his deepest appreciation to the staff and elected officials working for the cities of Cebu and Tagbilaran. Appreciation should also be extended to the Philippines' Department of Information and Communication Technology for their assistance in primary and secondary data collection. Finally, a special thanks to the citizens of the Philippines who shared their stories and outlooks on the future. 


\section{Introduction}

Access to Information and Communication Technology (ICT) has been powering the eDevelopment discourse for the past two decades. This ICT revolution has given way to a technological evolution coined Web2.0. Web2.0 has slowly been turning the focus of eDevelopment from technology to the individual. By this same token, governments and their actors are now utilizing these technologies through civic technologies and third party applications in order to stimulate citizen participation in the governance process. This has been seen as a positive step for development (Macintosh, 2004). Web2.0 technologies provide the masses with a platform to engage government through e-Participation and voice their political thoughts through eDemocracy. The 2030 Agenda for Sustainable Development encourages governments across the globe to promote responsive, inclusive, participatory and representative decision making at all levels of government, ${ }^{1}$ while the United Nations General Assembly recognizes the potential of eGovernment in promoting transparency, accountability and citizen engagement in public service delivery. ${ }^{2}$

The potential benefits for improving governance through the use of ICTs have been well documented (Hague and Loader, 1999; Moon, 2002; Macintosh, 2004; Labelle, 2005; Mossberger, et al., 2008); however this author would like to stress the word "potential." Governments are still inclined to focus on enhancing ICTs and e-Government services rather than on encouraging citizens to participate in the governance process (Burgess and Hougton, 2006; O'Toole, 2009; Verdegem and Hauttekeete, 2010; Jimenez, et al., 2012; Freeman, 2013). This is because investments in e-Government services have the prospective to increase efficiencies and lower costs; whereas, investing in e-Participation reduces the governments control over information and decision making (Thompson, 2005; Flamm, et al., 2006; Hernon and Cullen, 2006; Verdegem and Hauttekeete, 2010; Lester \& Hutchins, 2012). Moreover, research has shown that improvements in e-Government do not necessarily lead to improvements in e-Participation (Blakeley and Matsuura, 2001; Alampay, 2006; Cho, 2008; Kardan and Sadeghiani, 2011). To overcome these pitfalls, academics and institutions have been developing frameworks to promote e-Participation and democracy through socially inclusive governance. The most notable attempt at this 'access approach' is the "Socially Inclusive Governance Framework" introduced by the United Nations Public Administration Network (UNPAN) in their Global E-Government Readiness Report of 2005 (UNPAN, 2005). The advent of Web2.0 technologies into the e-Development discourse marked a seminal shift in the way citizens were perceived. E-Participation became an important point of debate; specifically related to the digital divide with a focus on equal access also referred to as social inclusion (Datar et al., 2008). UNPAN's model encourages governments to shed their emphasis on connectivity and access by substituting them with a focus on inclusion for all (see Figure 1).

${ }^{1}$ Target 16.7 of the United Nations' Sustainable Development Goals

2 UN General Assembly Resolution 69/327 
Figure 1: A Framework for Inclusion (Source: United Nations Global E-Government Readiness Report 2005

- From E-Government to E-Inclusion, UNPAN, 2005, pg.8)

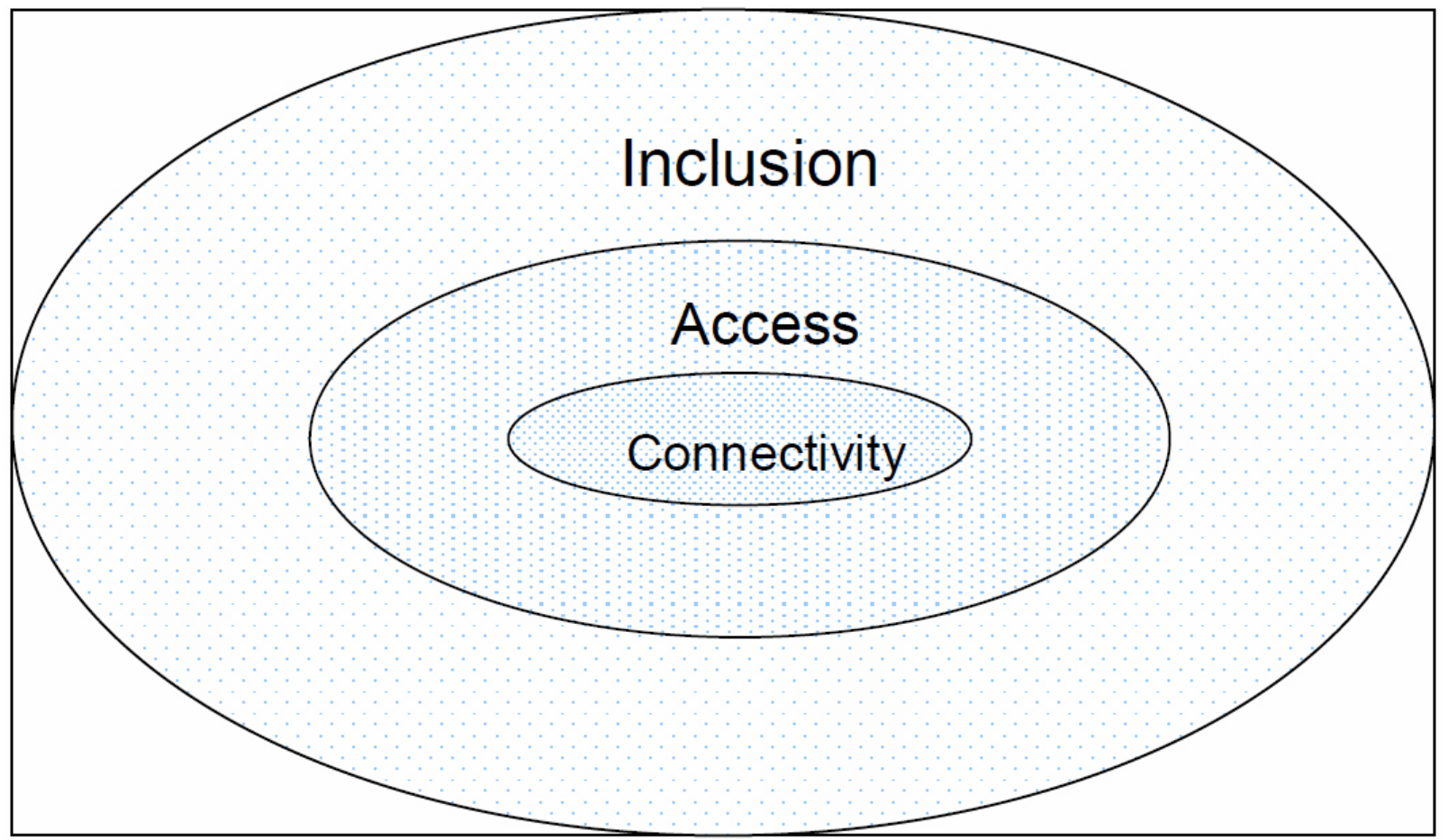

This framework or 'vision' for restructured thinking about how to improve e-Government sought to appreciate the capabilities of each and every person; the choices they make; and the freedoms they partake in (UNPAN, 2005, pg112). The foundation of the model was derived from Amartya Sen's work on the Capability Approach. However, this framework neglects Sen's philosophical argument within the context of e-Participation that the capability of individuals to convert resources into value should be observed, instead relaying on the expansion of opportunity through access, which is still at its core. The framework merely generalizes the necessity to focus on "the expansion of the 'capabilities' of people to lead the lives they value most;" while rich in narrative, it lacks specification and empirical support. Nevertheless, it is still one of the dominate policy models for crafting participatory e-Government initiatives. ${ }^{3}$

This article examines the relationship between government, their actors, and citizens through the use of Web2.0 technologies in an effort to understand the capabilities affecting citizen's opportunities to achieve value through e-Participation. Previous models for promoting the inclusion of citizens, like the one presented by UNPAN, have fallen short of truly identifying the capabilities necessary to become active participants in the governance process. This article will present an 'existential approach' to e-Participation that focuses more on the capabilities of individuals in order to cultivate responsive, inclusive and participatory e-Government initiatives.

3 This framework was used in the drafting of the Philippine E-Government Master Plan during the Benigno Aquino III administration, as discussed by Under Secretary Mon Abraham and one of its contributors Prof Erwin Alampay. 


\section{Inclusion in the Governance Process}

The field of research pertaining to e-Governance is not rooted in any one conventional discipline. The paths being paved, cross between a number of research domains, particularly Political Science, Computer Science, Information Systems and Public Administration (Heeks, 2007). A key element of this research is its interdisciplinary approach that incorporates the principal theories of human development and political science with the multidisciplinary field of e-Governance to present a new way of fostering e-Participation. It is therefore essential to provide a working definition of the key terms.

\subsection{Terminology}

E-Governance and e-Government are somewhat synonymous, while the terms are often used interchangeable, for the purposes of this article; e-Governance is a comprehensive term with the ultimate goal of strengthening the state through responsive, inclusive, participatory and representative decision making. Conversely, E-Government refers to the use of ICTs by government agencies to improve the delivery of information and public services to its citizens through transparent and accountable means. In order for this to take place, citizens need to engage in this electronic form of governance. This term is called e-Participation, which is defined as the sum total of both the government programs to encourage participation and the willingness of citizens to do so (UNPAN, 2005). E-Participation itself can be broken down into four eGovernment nomenclature. The first is Government to Government (G2G) which involves conducting electronic exchange between government-actors at all level of government. The second is Government to Business (G2B), which many e-Government services are designed to promote, such as online business permits and property tax payments. The third and fourth nomenclatures refer to Government to Citizen (G2C) and Citizen to Citizen (C2C). These classifications are at the heart of this research as they have a direct influence on socially inclusive governance. ${ }^{4} \mathrm{~A}$ final element of e-Participation is e-Democracy. E-Democracy is an umbrella term that broadly describes moving citizens from passive consumers of information to active ICT participants within the democratic/governance process (Garson, 2006; Backus, 2001; Lee, et al., 2011). While eGovernment tends to follow a top-down approach, e-Democracy tends to be bottom-up, although there are differing viewpoints on this (Clift, 2004; Coleman, 2005); nonetheless, E-Democracy at its core is predicated on the capability of citizens to take part in the governance process. In terms of scope for this article, e-Democracy is more than just online voting, it encompasses all aspects of citizen engagement and dialog through the use of ICTs; chiefly Web 2.0 technologies and civic technologies, which are sometimes one in the same. Once Web 2.0 technologies such as social media sites, wikis, and folksonomies become integrated into e-Government solutions they become civic technologies. These include public and private sector applications as well as e-Government infrastructure. The "Evolutionary E-Governance 2.0 Framework" illustrates these terms within the governance process (see Figure 2).

${ }^{4}$ Civil society also falls under the classification of G2C and C2C, but the focus of this article is on individual capabilities and not particularly the "third sector" of society. 


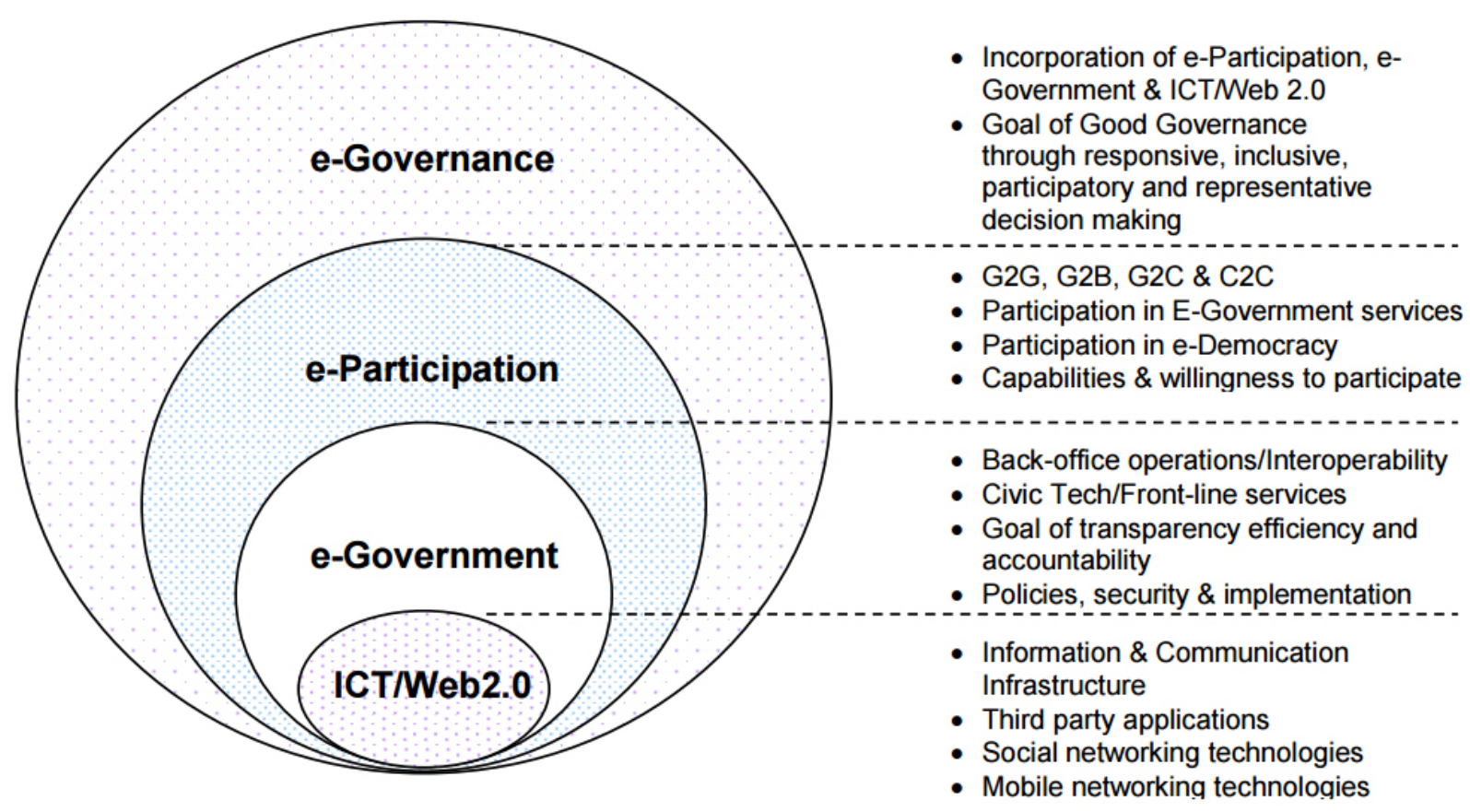

Lastly, the governance process itself is a system. The most noteworthy of these systems is David Easton's theory of a political system which he introduced with his 1965 publications of A Framework for Political Analysis (Easton, 1965). This approach encapsulates the field of systems theory; however, this orthodox interpretation of a political system requires substantial modifications to be used as a model for e-Participation. This article, as a working definition, interprets the governance process as a democratic system that promotes responsive, inclusive, participatory and representative decision making, with the goal of providing instrumental as well as intrinsic value to citizens through e-Participation; similar to Nath's ICT empowerment loop, which asserts that individual participation in governance can have a multiplier effect as citizens gain greater control and capacities to act, so too does e-Participation (Nath, 2003).

\subsection{Identifying the Models}

With e-Governance research crossing a multitude of disciplines, establishing a model that can provide policy makers with a normative understanding of the conditions affecting citizen's capabilities to participate electronically can be a challenge. Here is where applying a systems theory model like Easton's falls short as it does not account for the capabilities of individual or the dynamic environment in which e-Participation takes place. Easton finds it useful to distinguish the environment from the political system or settings in which it operates (Easton, 1957 pg.384).

In the United Nations' most recent report, e-Participation is still an evolving concept. The report sharpens its focus on policy decisions that better reflect the needs of citizens, while expanding its access approach to include more current technologies such as tablets, cloud computing and open data (UN, 2016, pg.51). Although this is a positive step for achieving the Sustainable Development 
Goals (SDGs), it does not resolve the shortcomings of its approach. When evaluating the level of entitlements, both the range of communication options and the ability of citizens to make use of these options to achieve their relevant functionings are important (Garnham, 1997, p.34). Garnham, like Sen, rejects the idea of using resources as a tool for measurement and instead turns to the 'beings and doings' of individuals, such as being well-nourished; these beings and doings are what Sen refers to as 'functionings' (Sen, 1992 p.5). Another notable endeavor at using the Capability Approach comes from Professor Erwin Alampay. Alampay's framework addresses Sen's philosophical argument by accounting for the reasons why people use ICTs and to what end value is achieved, but stops short of properly identifying the capabilities necessary to achieve that value (Alampay, 2006, p.9). Within Sen's approach, achieved value can be instrumental, as in a means to an end, or intrinsic, in and of itself (Sen, 1992, p.31). Analogous to the UNPAN framework, Alampay's model illustrates how Sen's approach can be applied to universal access, but in a way that prioritizes the individual's socio-economic condition (see Figure 3).

Figure 3: The Capability Approach Applied to Access to ICTs (Source: Alampay, 2006 p.9)

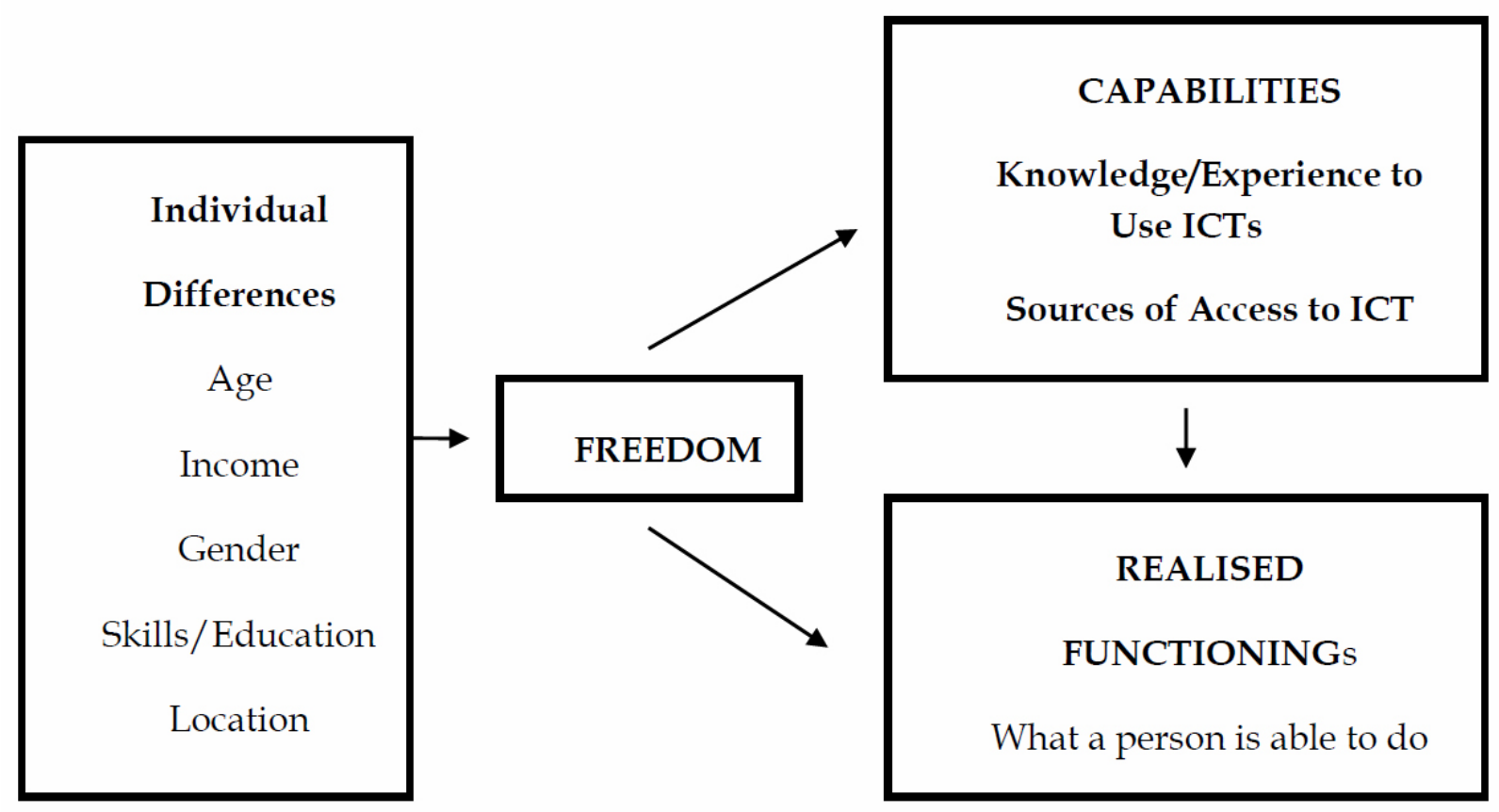

Alampay rightly identifies access as a capability which is a gateway to other opportunities, but does not succeed in identifying barriers or capabilities beyond knowledge acquisition that may lead to realized functionings. This article will provide philosophically and scientific evidence to support its normative framework for improving e-Participation in the governance process. This framework incorporates the philosophical ideals of Sen's capability approach, while addressing shortcomings in Easton's systems theory approach to governance as well as Alampay's applied approach to universal access. 


\section{E-Participation in the Philippines}

The Philippines was selected as the research site for this study based on its aggressive push to improve information and communication infrastructure (ICI), e-Government, and most notably eParticipation. Its citizens rank first in the world in time spent on social media (four hours and seventeen minutes per day) and sixth among countries with the largest number of active Facebook users (sixty-three million). ${ }^{5}$ Although the Philippines has a high penetration rate of mobile phone technology of more than one per citizen and improved ICI through policies like Executive Order No. 265, s. 2000, e-Participation regressed substantially over a nine year period from 2003 to $2012 .{ }^{6}$ This reverse correlation between ICI and e-Participation can be seen below (see Figure 4).

Figure 4: UN E-Government Survey Data for the Philippines (Source: UNPAN Data Center: https://publicadministration.un.org/egovkb/en-us/Data-Center, accessed: 10/27/16)

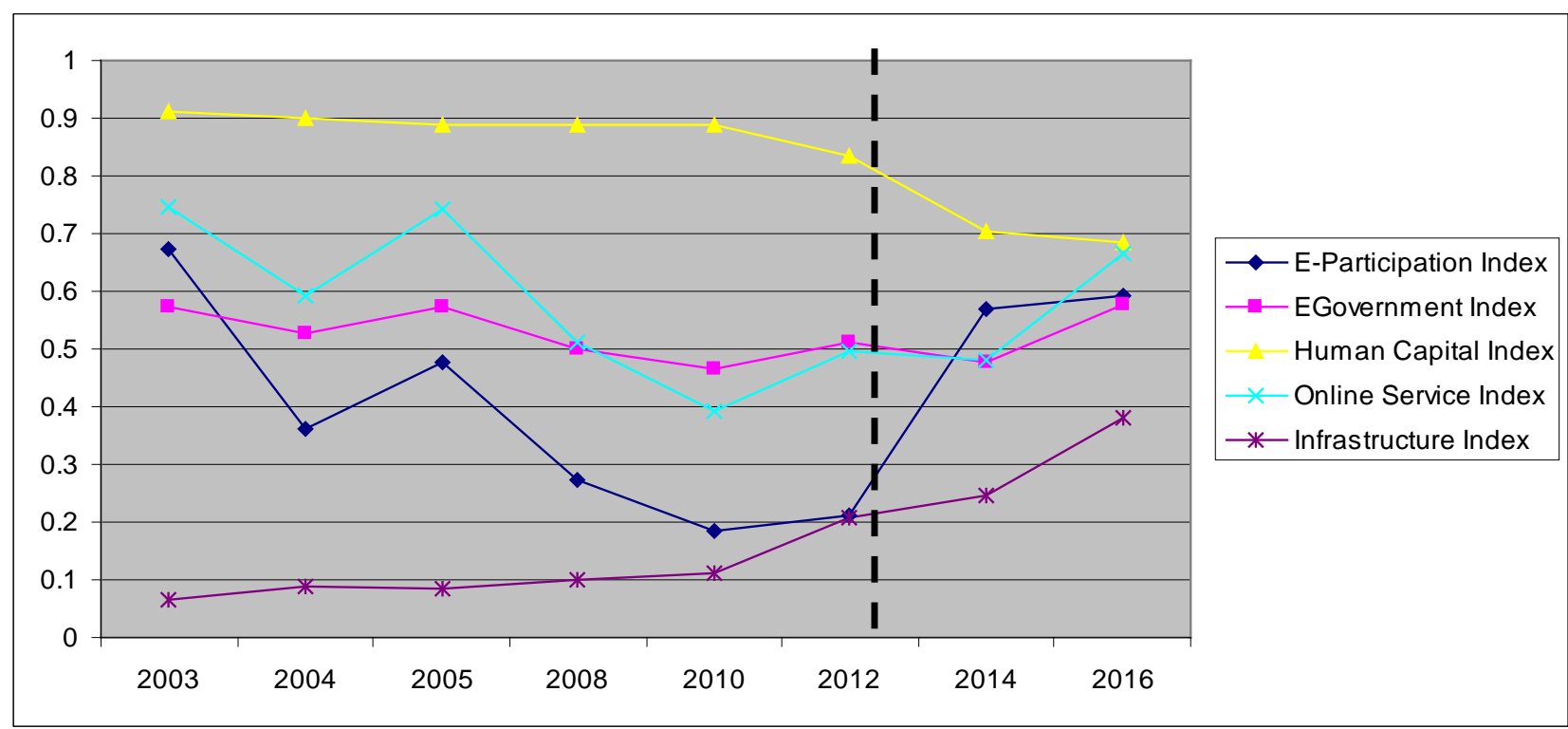

The research for this article commenced in June of 2013 which is distinguished by the dotted line in Figure 4. What makes the Philippines an interesting case is that prior to 2012 the Philippine government was following UNPAN's model presented in Figure 1. Moreover policy and strategies were being crafted by the Arroyo administration (through the Philippine Digital Strategy Paper) and the Aquino administration (through the E-Government Master Plan) based on the information obtained from the UNPAN reports. This strategy was echoed by the Information and Communication Technology Office's (ICTO) Deputy Executive Director during an interview. Not until recently has the reverse correlation between ICI and e-Participation corrected itself, mainly due to the centralization of e-Government services and web hosting through Administrative Order

5 The statistics were compiled by UK-based consultancy We Are Social Ltd. and reported by the social media management platform Hootsuite (https:/ / wearesocial.com/uk/, accessed 09/01/2017)

${ }^{6}$ E.O. 265, s. 2000 by President Joseph Ejercito Estrada approved and adopted the Government Information Systems Plan (GISP) as a framework and guide for all ICT efforts in government. 
No. 39. Additionally, the ICTO, which as of May 23, 2016 has become the Department of Information and Communications Technology (DICT) through Republic Act No. 10844 has focused its efforts on addressing the key e-Participation indicators of the biennial UN E-Government Survey. Unfortunately, the vast majority of the indicators are supply driven and do not factor-in the existential capabilities of citizens to convert these opportunities and services into value. Without value, there is little incentive for citizens to participate in the governance process; hence, subduing e-Democracy and ultimately weakening the state in areas of inclusive, participatory and representative decision making, all key indicators of Target 16.7 of the SDGs.

\section{Research Design}

As alluded to at the beginning of this article, e-Participation involves the bringing together of citizens, technology and government. To meet the objectives of the research, each of the three 'spheres' were examined using a combination of methods. While each sphere is unique, there are substantial overlaps. For example, social media applications like Facebook are now routinely implemented as civic technologies. Facebook offers public figure accounts as well as 'pages' for city hall and community interaction, whereby expanding the opportunities for citizens to interact with government and the government's opportunity to engage citizens. Furthermore, any eGovernment program by definition will amalgamate all spheres of e-Participation when deployed. The next two sections outline the objectives and methodologies used for this research.

\subsection{Research Objectives}

The primary objective of this research was to challenge the orthodox view that access is the principal driver for encouraging socially inclusive governance through e-Participation and to develop a more citizen centric model to cultivate responsive, inclusive and participatory eGovernment initiatives. This was accomplished by a) examining whether citizen engagement through the use of Web 2.0 technologies is benefiting the government and the citizens they serve through a deepening of democracy by way of citizen engagement, transparency and accountability; b) documenting the effects e-Government services and Web2.0 is having on the capabilities of citizens to enhance their opportunities and achieve value through e-Participatory activities and explore the shift in power that is taking place between politicians and the citizens they serve; and c) developing a capabilities approach framework that alters the emphasis of the policy and development discourse away from an access approach for promoting and encouraging e-Participation to one that focuses more on the existential capabilities of citizens. By evaluating the social arrangements, not just the resources, affecting citizens' decisions to participate in eGovernment an existential approach may lead to an increase in socially inclusive governance, whereby empowering citizens and strengthen the state through a deepening of democracy. By meeting these objectives, the central research question could be answered; namely, "what are the capabilities affecting citizen's opportunities to achieve value through e-Participation" a question that has been suggested by academics and institutions working in the fields of e-Governance and human development, yet neither supported with convincing evidence nor presented with any degree of theoretical rigor. 


\subsection{Research Methodology}

In order to meet the objectives of this research a mixed methods approach was taken. Priority was given to the qualitative data utilizing a sequential exploratory strategy. This method is especially advantageous when building new instruments (Creswell, 2003, pg215-216). A semi-inductive approach was taken to identify the core set of capabilities after testing the underlining hypothesis, which holds that, H0: "Access to Information and Communication Technologies is no longer a prominent barrier to e-Participation." By providing sufficient evidence to not reject the underlying hypothesis, a more existential model was theorized and supported with scientific evidence in the Rawlsian tradition.

\subsubsection{Technology Sphere}

Within the Technology sphere, two government programs were identified for case study, the TV White Space Initiative (TVWS) and the Technology for Education, Employment, Entrepreneurs, and Economic Development (Tech4ED) program, which is closely tied to TVWS and will ultimately be providing the internet connectivity to Tech4Ed. The case study method was used as an empirical inquiry that investigated a contemporary phenomenon (e-Participation) within its real-life context (socially inclusive governance); where the boundaries between phenomenon and context were not clearly evident (Yin, 1984, p23). Third party Web 2.0 applications such as YouTube, Twitter, Skype and Google+ were initially studied; however, Facebook was determined as the primary G2C interface to be documented due to its large user base and penetration rate. ${ }^{7}$ By examining these cases studies, linkages could be made between phenomenon and context to better understand the capabilities needed for citizens to achieve value through e-Participation. The technology sphere has broad overlap with the other two spheres in this study.

\subsubsection{Government Sphere}

For the Government sphere an ethnographic approach was used in the field to observe traditional G2C interaction between citizens and local politicians as well as to evaluate the role that Web 2.0 technologies play in the governance process. In total, four field visits were conducted in the Philippines from June of 2013 to April 2017. Three local politicians were identified for ethnographic study over the period of a full administrative term. ${ }^{8}$ This included traditional interactions between politicians and citizens such as office visits, town hall meetings and pulong-

7 Facebook is the dominate Web 2.0 social media application with over 1.87 billion active users. It holds a $18 \%$ market share, which is $7 \%$ more than the next closest competitor that is also owned by Facebook (https://www.statista.com/, accessed 09/01/2017); additionally, Facebook as a penetration rate of 52\% in the Philippines or approximately 54 million Filippino users (http://www.internetworldstats.com/asia.htm, accessed 09/01/2017). It is the most popular social media platform in the Philippines beating out its closest competitor Google+ by $8 \%$ (https:/ / wearesocial.com/uk/, accessed 09/01/2017).

8 The administrative term lasted from June 30, 2013 to June 30, 2016; however, the ethnographic research actually extended until April 12, 2017. 
pulong which are formally arranged gatherings as well as the daily monitoring the politician's Facebook accounts. This provided additional insight into how government actors interact traditionally and virtually within their communities to promote social inclusion and democracy. In total, 3,918 Facebook posts as well as 19,998 comments were reviewed and documented. Additionally, an appraisal of all major national ICT policies and strategies related to eParticipation were reviewed dating back to the Estrada Presidency of 1998 2001. Finally, qualitative data was collected though in-depth interviews with key informants from the DICT as well as local e-Government administrators at the City of Cebu and the City of Tagbilaran to triangulate and strengthen the findings.

\subsubsection{Citizen Sphere}

Data collection on citizens was carried out through interviews and questionnaire/surveys collected from citizens in the two major metro regions of the Philippines, Manila and Cebu. 144 interview hours were logged. Additionally, participants were given the option of filling out the questionnaire/surveys in English, Tagalo or Cebuano. ${ }^{9}$ Best efforts were made to obtain a random sample of Filipino citizens. Of the 466 Filipinos surveyed, 249 were female and 217 were male. The age of respondents totaled 275 between the ages of 15 21; 115 between 22 34; 64 between 35 54; and 12 respondents were over the age of 55, in-line with the Philippines' bottom heavy population pyramid which boast an median age of 23.3 based on 2010 census data from the Philippine Statistics Authority. Of the 14 regions that make-up the Philippines only Davao in region 11 was not represented. The classification of citizens by income was reasonably distributed with $27 \%$ coming from Class E, 31\% coming from Class D; 29\% coming from Class C; and 13\% coming from the upper classes, Class A\&B. ${ }^{10}$ Prior to administering the questionnaire/surveys, an exploratory study was done to help narrow down the capabilities affecting citizen's participation in the governance process. This included interviews with academics working in the field of eGovernance research in the Philippines. It was determined from the exploratory study that the uprising intellectual class was the main proponents of e-Participation activities in the Philippines, as such, it was deemed important to engage in dialogue with young university students. In addition to the questionnaire/surveys six round table discussions were carried out at two universities in the National Capital Region, the University of the Philippines, Diliman and Ateneo de Manila University.

9 Tagalo is one of the official languages of the Philippines and is the most spoken language in Metro Manila. Cebuano, colloquially called Visayan, is the official language of the Visayas and the most spoken language in Cebu and Tagbilaran.

${ }^{10}$ Income level by socioeconomic class is defined by the Philippine National Convention on Statistics (NCS) as: Class E 0 5200php; Class D 5201 1600php; Class C 16001 50000php; Class A\&B 50001 150000php; class $\mathrm{A} \& \mathrm{~B}$ are considered high-income, while class $\mathrm{C}$ and $\mathrm{D}$ are middle to low-income. Citizens in class $\mathrm{E}$ are the lowest of the socioeconomic classes and typically reside in squatter communities. 


\subsubsection{Building the Existential Model for E-Participation}

Before determining the capability set, the research hypothesis had to be tested. To test the hypothesis the capability of 'access' was broken down into three indicators as defined by the World Summit on the Information Society (WSIS) and the International Telecommunication Union (ITU). ${ }^{11}$ The three most prominent barriers to access are availability of service; ability to use the internet; and cost of internet access. These barriers may also refer to inequalities between individuals, households, or geographic areas, usually at different socioeconomic levels or other demographic categories - this is known as the digital divide. The questionnaire/surveys were the primary source of data, analyzed by SPSS Ver.22 using binomial testing, bivariate correlation analysis and chi-square cross-tabulation. The significance level for the p-value was set at 0.05. Once the hypothesis could not be rejected the study turned to isolating its normative set of capabilities utilizing a semi-inductive approach. The criteria for the selection of capabilities was predominantly based on Ingrid Robeyns' five criteria for the selection of capabilities, which requires explicit formulation; methodological justification; sensitivity to context; different levels of generality; and exhaustion and non-reduction (Robeyns, 2003, pg. 70). Findings from the three spheres of e-Participation were used to constrict the core set of capabilities to be used in the Capabilities Approach Framework for E-Participation presented in Section 5.2., which draws on the philosophical foundation of Sen's capability approach for human development and Easton's theory of a political system. The next section presents these findings.

\section{Research Findings}

The research findings have been divided into four sections. The first section tests the underlying hypothesis, which challenges the access approach model for e-Participation. The remaining three sections provide support to the hypothesis while addressing the objectives set forth for this research. The technology sphere examines civic technologies and third party applications; the government sphere explores e-Participation through the lens of the politician; and the citizen sphere examines citizen engagement and their perspectives on e-Participation in the governance process.

\subsection{Testing the Hypothesis}

The underlining hypothesis for this research is predicated on the fact that access is no longer a barrier to inclusion. To test this, the following hypothesis was raised H0: "Access to Information and Communication Technologies is no longer a prominent barrier to e-Participation." Once there was sufficient evidence to not reject the underlying hypothesis, the research employed qualitative methods to identify the capabilities needed to cultivate e-Participation then substantiated the capability set with qualitative and quantitative evidence. As introduced in Section 3.2.4. The three

11 These indicators are based on a mix of WSIS Action Line Items and the ICT Development Index (IDI) published by the United Nations International Telecommunications Union (ITU) which is based on internationally agreed upon ICT indicators for access. 
indicators for testing the hypothesis are availability of service; ability to use the internet; and cost of internet access.

To test Internet availability, the data collected through questionnaire/survey was stratified by gender, age and income with little to no discrepancies between each group. Citizens between the ages of 22 to 34 had the lowest percentage of Internet availability at $78.2 \%$, while high income Class A \& B citizens had the highest percentage of Internet availability at $98.2 \%$.

The leading perception regarding the ability to use the internet is focused on age, with youth historically having a broader capacity to learn and use ICTs effectively while the elderly are more limited in their capability. To test this perception, three indicators were examined, the ability to text on a mobile phone; the ability to make use of the Internet; and the ability to use a computer. The ability to text with a mobile phone was positive regardless of age ranging from $89.7 \%$ to $100 \%$. For Internet usage there was a significant correlation between age and the ability to use the Internet, with citizens aged 15 21 having a 97.5\% (268 respondents) positive response and citizens aged fifty-five or older having only a $45.5 \%$ (5 respondents) positive response. The ability to use a computer fared slightly better, but also showed a significant correlation between age and computer usage with citizens aged 15 21 having a 98.5\% (271 respondents) positive response and citizens aged fifty-five or older having a $63.6 \%$ (7 respondents) positive response. The final barrier that was tested had interesting results.

For cost of Internet access, the study looked at income as the unit for measurement. The chisquared test returned a p-value of .261; while not outstanding the expected outcome showed that Class E citizens with a lower income were more likely to perceive the cost of Internet as cheap, while citizens in Class A \& B perceived the cost of Internet to be more expensive. This was reinforced by a strong pearson correlation of -.148 with a sig. (2-tailed) value of .002. Figure 6 illustrates the chi-squared test by showing the outcome and expected outcome, with the number of respondents represented on the y-axis (see Figure 6).

Figure 6: Cost of Internet Service by Socio-Economic Class (source: author)

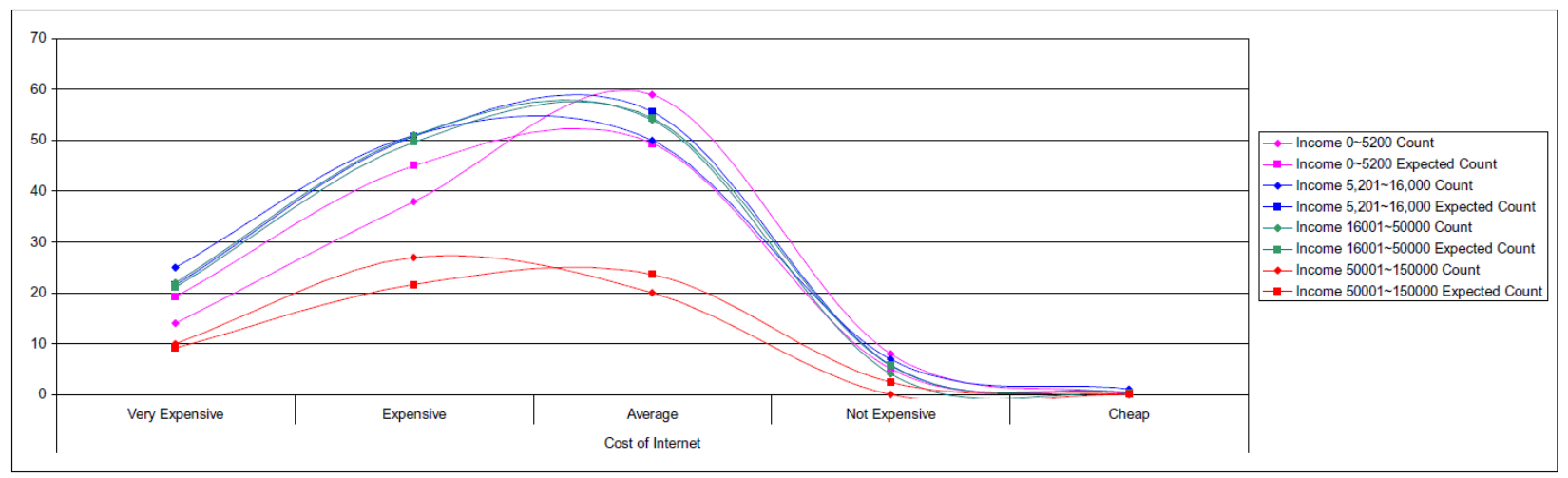

Results from the qualitative researched revealed that citizens in the lower socio-economic classes tended to use hot-spots or free Wi-Fi services offered in shopping malls or other similar venues, while citizens from the upper classes had monthly contracts with telecom providers. While all social-economic classes had access to the Internet, their methods of accessing it were 
considerably diverse. Based on the results from the quantitative research, the hypothesis could not be rejected. While age does influence the ability of citizens to use certain ICTs, it does not affect the availability of Internet access or the cost of obtaining it. Access should still remain a core capability, but it is no longer a prominent barrier to e-Participation and should be viewed more as a gateway capability as suggested by Alampay.

\subsection{Civic Technologies and Third Party Applications}

The first case study, the TV White Space Initiative (TVWS) was designed to provide free wireless data connectivity throughout the country by repurposing unused television frequencies in the VHF and UHF bands. TVWS was approved by the Federal Communications Commission (FCC) for data communication in 2010 and was first implemented by the Philippine government in 2014. It is based on the IEEE802.22 standards set by the Institute of Electrical and Electronics Engineers (IEEE). TVWS utilizes broadcasting frequencies in the wireless spectrum that are being left unused as the country switches to a fully digital television network. The use of hybrid and wireless spread spectrum technologies for low-cost last mile connectivity have been well documented (Huffman, 2002). According to DICT's Regional Cluster Director tasked with overseeing its pilot testing, TVWS will use the vacant analog TV frequencies in the UHF and VHF range (between $54 \mathrm{MHz}$ and $806 \mathrm{MHz}$ ) which will deliver up to 6 megabits per second of data throughput at maximum range of 10 kilometers. In reality, the data throughput rates are much lower and using Web 2.0 application such as YouTube and Facebook can be somewhat trying. Moreover, the government must partner with the private sector to build-out the Information and Communication Infrastructure that requires an extremely high initial investment. DICT is only offering two year contracts to telecom providers, who must front large infrastructure costs, without the safety of a long-term contract. This has hindered deployment. The Regional Director has said full deployment is still two to three years away and other low-cost wireless technologies are also being tested. While TVWS has the potential to enlarge citizen's choice in access, it is still years from becoming a reality and has no effect on the capabilities of citizens to participate in the governance process beyond supporting the second case.

The second case study, the Technology for Education, Employment, Entrepreneurs, and Economic Development (Tech4ED) evolved from the Philippines Community eCenter Program $(\mathrm{CeC})$. This program was started by the Department of Information and Communication Technology (DICT), to promote citizen participation in e-Government services and provide IT education to the masses; specifically the underserved and marginalized citizens within the country. Based on interviews with two Tech4ED project managers at DICT, it was determined that the main goal of Tech4Ed is to enlarge the capabilities of citizens through relevant ICT-enabled services and content for socio-economic development; specifically in underserved communities with the aim of improving citizen's well-being. This study examined DICT's four main objectives for this program. The first objective is to establish sustainable Tech4ED centers throughout the country. This has been quite successful and is likely a best practice example for rural telecenter deployment. DICT has moved from a Local Government Unit (LGU) based initiative to a multisectorial stakeholder approach which has allowed them to deploy 863 Tech4ED centers as of December of 2016. While visiting a Tech4ED center in Quezon City, citizens without a student ID 
were not allowed to use the facility. This is an example of policy being set at the national level not propagating to the local level. The second objective, content development addresses Alampay's concern for fostering knowledge acquisition; however, it was found that while robust, the content provided at the Tech4ED centers were almost exclusively in English, which for a country with two official languages, nineteen regional languages and over one-hundred dialects, creates a considerable barrier to many Filipinos; especially citizens with limited education and literacy. The third objective aims to build the capability of Tech4ED Center Knowledge workers; this has been successfully achieved through training courses and support at the national level. The final objective is the advocacy and promotion of the Tech4ED Centers. Currently there are 35,824 registered users as of December 2016. The program has also established a social media presence on Facebook with 14,425 likes and 14,351 followers as of December 2017. This project touches upon two important capabilities, knowledge acquisition and equality. Knowledge acquisition is discussed in both access approach models, but not clearly defined. From the perspective of Nussbaum this is an internal capability that if fostered could become a combined capability through government support (Nussbaum, 2000). ${ }^{12}$ The second capability 'equality' means having the same opportunity to access information as ever other person; not only 'paper freedoms,' but real opportunities as defined by Sen in his 1984 Dewey Lectures (Sen, 1985).

\subsection{E-Participation through the Lens of the Politician}

Over a three year period which ended in April of 2017, a plethora of data was collected on three politicians. Two of the politicians were city councilors for the City of Cebu representing the Bando Osmeña Pundok Kauswagan (BOPK), which is currently affiliated with the Liberal Party and one is the current Mayor of the City of Tagbilaran. All three case subjects preferred to use Facebook as a means of interacting with their constituents online, although Councilor Cabarrubias was active across many Web2.0 platforms. By examining e-Participation habits between politicians and citizens, patterns could be established to provide guidance in identifying and substantiating the types of capabilities that are fundamental for broadening e-Participation and socially inclusive governance. Substantial 'spikes' in Facebook activity were carefully reviewed. Each of the politicians used social media in different ways. Mayor Baba Yap received a tremendous amount of comments and shares around the time of the Bohol earthquake and subsequent typhoon Yolanda; a $183 \%$ increase in comments and an astonishing $442 \%$ increase in shares on the year. During the earthquake the City's website and all its servers went down; however, since Facebook is a third party platform, it continued to function. Mayor Yap was able to interact with citizens providing them with incident reports, where to find relief goods, power updates, class suspensions and advisories, as well as 'hotline' information for contacting public safety services. Citizens were able to share this information with people in their social circles whereby empowering others through increased engagement and distribution of critical information. It is worth noting that TVWS was providing emergency Wi-Fi coverage during this time. While early in his term, feedback was

\footnotetext{
12 Nussbaum in her book " Women and Human Development: The Capabilities Approach " argues for ten central capabilities that should be supported by all democracies.
} 
limited, later on; Mayor Yap assigned staff to provide feedback to citizens via his Facebook account. Figure 7 breaks-down Mayor Yap's Facebook activity over the three year period of his inaugural term (see Figure 7).

Figure 7: Facebook Activity for Mayor Baba Yap (source: author)

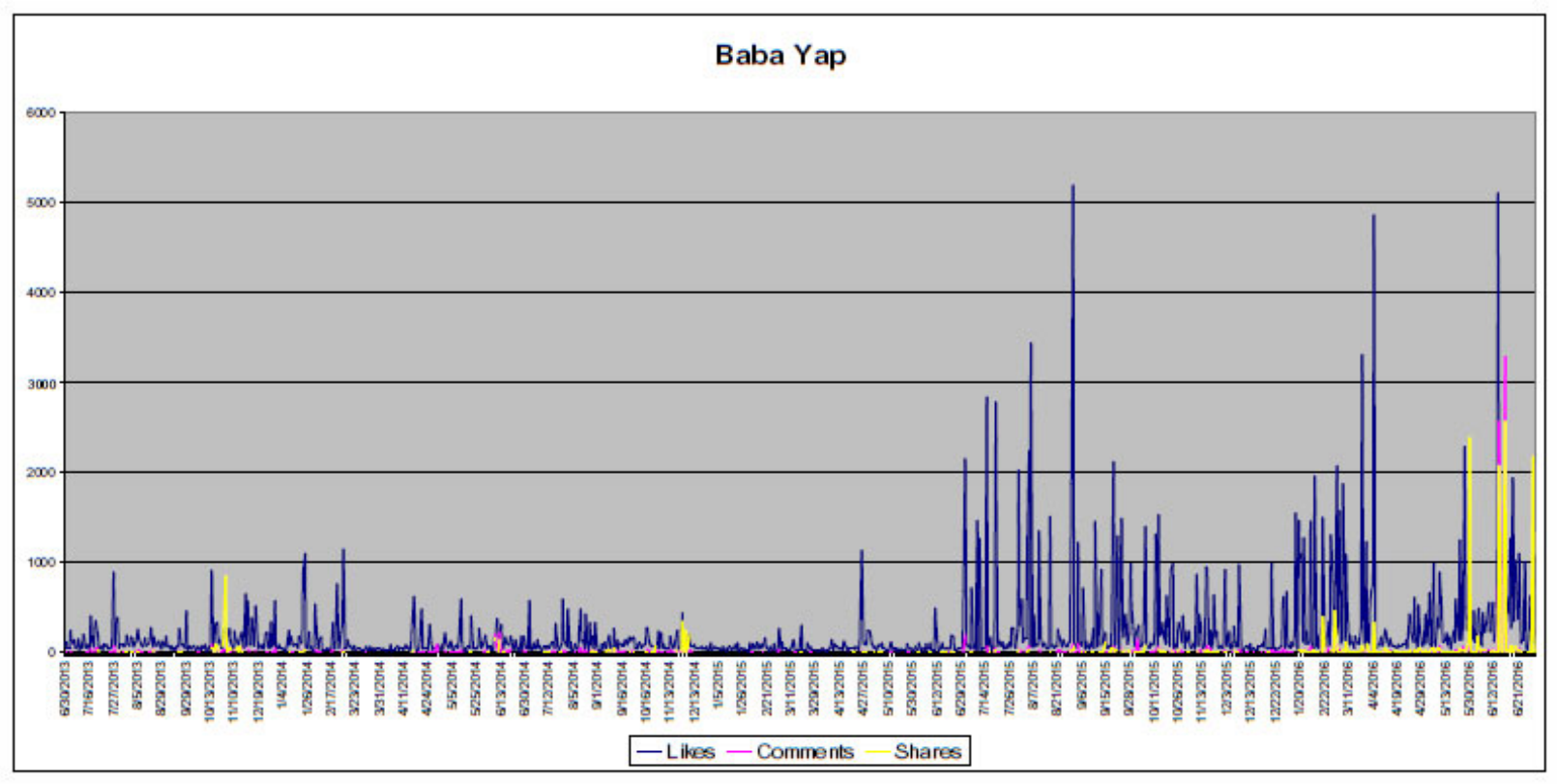

Mayor Yap was also able to utilize his Facebook page to engage citizens on legislation such as Republic Act 9994 related to senior citizens. The legislation received 180 comments from citizens with an additional 294 shares. Mayor Yap's most successfully use of social media was in offering prize money to citizens that could guess the outcome of NBA playoff games, often generating over 2,000 likes with comments reaching up to 3,281. In some ways this reinforces the old patron-client relationship by providing instrumental reward in addition to intrinsic value through public recognition of achievement. No additional observation of patronage was apparent. Councilor Cabrera of Cebu City balanced her traditional political interactions with her social media interactions, often using Facebook as a way to promote her environmental agenda as Environmental Committee Chairperson. Her 'wall' fostered a virtual community made-up of likeminded politicians and environmentally conscious NGOs such as the Coastline Management Board (CMB). She encouraged e-Participation with citizens by providing them with information regarding proposed ordinances whereby fostering e-Democracy. Citizens were able to post comments and receive feedback directly from the Councilor. Additionally she would post information regarding public hearings as well as livelihood training to improve the daily lives of her constituents. The second Cebu City Councilor, Councilor Bob Cabarrubias linked social media platforms together such as Skype, YouTube and Facebook. All City Council sessions were streamed live via Skype, which could be accessed from his Facebook page. Citizens could quickly interact with him and he often responded to inquires in-person. Similar to Councilor Cabrera, Councilor Cabarrubias used Facebook as a portal to initiate new ordinances and provide information on training to his online community of 'friends.' Additionally, he would provide information on job opportunities, which citizens could inquire about. It was also common practice 
for Councilor Cabarrubias to post photos and information regarding citizens that would visit his office. Unlike the national government which only operates in English, all politicians studied used the local language Cebuano (Visayan) interchangeable when communicating with citizens. Citizens could find value in accessing information in a format they could understand and express their views in an environment free of discriminatory behavior; moreover, they were able to share posts with friends and family creating a virtual community around topics raised through socially inclusive interaction. The government sphere put forward two additional capabilities central to achieving value through e-Participation; they are expression and affiliation. Expression overlaps with Nassbaum's core capability of control over one's environment, which highlights the need to be able to speak freely and exercise one's political choice (Nussbaum, 2011). Affiliation is another existential capability that makes Nussbaum's list of core capabilities. It is the capability to interact socially and have the freedom to assemble without the fear of reprisal or oppression. It also enables local politicians to leverage social media to rally citizens around a public cause such as air pollution, noise ordinances or benefits for senior citizens. If adopted correctly, it deepens democracy through responsive, inclusive, and representative decision making.

\subsection{Citizen Engagement and Perspectives}

When interviewing citizens at random about e-Participation, distinct patterns could be identified. Trust was a reoccurring theme. Trust in government and trust in technology. Especially in the rural areas like Bohol, citizens rather visit government offices than interact with government online. So while the United Nations General Assembly recognizes the potential of e-Government to promote transparency and accountability, the average citizen is still skeptical. In seventeen cases, the citizen being interviewed had no idea there were e-Government services that promoted citizen engagement. Of the ones that did, only four citizens interviewed had positive comments such as it makes things easier, convenient and hassle free; it's effective; and it's important for accessing services. As for e-Participation itself, the responses were more positive. Citizens felt they could use Web 2.0 technologies to exercise their right to be heard; to expand their network; to find work; to gain information about their government; and to share their concerns with other likeminded people. This reinforces the capabilities identified in the previous three subsections. The most heated dialogue centered on the power relationship between citizens and government actors. Some citizens felt that politicians are only visible or accessible to people during campaigns and "become invisible after they win the election." However, the research showed that Mayor Yap and Councilor Cabrera's posting patterns did not deviate from their norms, from the time of filing for re-election until the election results were announced. ${ }^{13}$ Nevertheless, additional comments taken from interviews with citizens during field research exposes that citizen's feel politicians can still control the information released and while citizens can easily express their views, they sometimes do so "under threat;" moreover, e-Participation can have the reverse effect, "politicians use ICT to gain fame and have the citizen patronize them." Other citizens interviewed saw no change or that their problems never change, "the only difference is we have technology"; "although the people

\footnotetext{
${ }^{13}$ Councilor Cabarrubias did not file an application to run for a final term.
} 
have more information and easier access to those information, politicians are still unshakeable with their power;" for these people the value of participating in the governance process is "still what it is after the social media started becoming active." However, the majority of citizens see the power relationship shifting towards the masses; this was reinforced during the roundtable discussions. For most Filipinos social media has changed the balance of power. As one of the students from the roundtable discussions mentioned "the people, especially the youth, have become more exposed to the happenings in government through ICTs. They have also been more vocal online on their opinions regarding the government as compared to 10 years ago." A pattern in the responses became more evident as citizens expressed they have more power because they can "point out the flaws of the government" using social media; moreover, "people acquire the power to express themselves because of this" and "the voice of the people cannot easily be ignored." One of the most absorbing comments came from a young male from the Calabarzon/Mimaropa region who said "social media has become the modern EDSA for people to protest for or against something or someone;" 14 or as stated by other citizen, "the masses uses social media therefore, more people are able to see opinions and in turn, change other people's opinions," as was the case of the Million People March. ${ }^{15}$ When surveyed about social media's effect on the power relations between citizens and politicians, 18\% (77 respondents) said there was no affect, while 16\% (70 respondents) said social media gave more power to the politicians; however an overwhelming 66\% (280 respondents) felt social media is changing the rules of the game and leveling the playing field for citizens. Two-factor ANOVA testing was run to see if income or gender had any bearing on the results, but no correlations could be found. Based on the qualitative interviews with support from the quantitative data, there has been a perceived shift in the balance of power towards the masses. Findings from the ethnographic research also support this claim. The next section introduces the capability set and how these normative capabilities fit into the broader e-Participation model for socially inclusive governance.

\section{Capability Approach to Social Inclusion}

Based on the findings from this study, there are five central capabilities that affect citizen's opportunities to achieve valued through e-Participation. This core set of normative capabilities focuses on the existential conditions of individuals and provides an alternative way of thinking about the modality of socially inclusive governance through e-Participation.

14 EDSA is in reference to the "People Power Revolution" that took place in the Philippines (1986 \& 2001). The People Power Revolution was a set of political protests to peacefully over throw the government.

15 The Million People March was a social movement that spared a series of protests in the Philippines to abolish the Priority Development Assistance Fund, more commonly referred to as the 'pork barrel' fund that was being used as a discretionary fund to defraud tax payers of nearly 10 billion Philippine pesos. Pressure from social media and the protests expedited the Supreme Court's decision to rule the PDAF unconstitutional by August of that same year. 


\subsection{Selection of Capabilities within the Philippine Context}

The first capability coincides with the access approach, which is the capability to have affordable access to ICTs with low barriers to entry. This includes access to government resources to cultivate e-Participation. Equality important is the capability to speak freely without the fear of retribution. It was evident from the study that while citizens felt e-Participation can be empowering, it also left them vulnerable to the will of politicians. Citizens were skeptical about expressing themselves and held considerable distrust in government as well as in the technology itself. The next capability, having equal opportunity and freedom to participate in the governance process is closely linked to the previous capability. As the research showed, findings from the government sphere were mixed. While the ethnographic researched showed Web 2.0 technologies such as Facebook has leveled the playing field policies set at the national level are not always being implemented at the local level. The fourth capability, knowledge acquisition is the means to understand and access relevant information that will allow for socially inclusive governance. The capability of citizens to be able to acquire knowledge through e-Participation is often dependent on the options they have available. As the findings showed from the technology sphere, e-Government programs like Tech4ED created language barriers that excluded citizens with a poor command of English. This barrier was reinforced by students in the round table sessions. Discoveries from the ethnographic research reviled that all three politicians overcame this barrier by communicating with constituents in their local language and dialects. The final capability affiliation is the ability to interact socially and have the freedom to assemble. It plays a strong role in e-Democracy as demonstrated by all three politicians who used Facebook to foster communities around certain causes or policy discussions. This created value for both the politicians as well as the citizens they served.

The core set of capabilities presented in this article are explicit and empirically defendable as a normative list within the Philippine context. It is the author's expectation that the list is also methodologically justified, exhaustive and non-redundant; moreover, the level of abstraction at which this list has been introduced conforms to the philosophical ideals of the capability approach as laid out by Robeyns, with the exception of her criterion for different levels of generality. While this list does not boost universality, it does present a normative set of capabilities that can be tailored to each country and used in cross-country comparisons.

\subsection{Existential Approach for E-Participation}

Where UNPAN's framework for inclusion falls short is in assuming that capabilities are purely defined as the access and opportunity to do things a person values most (UNPAN, 2005 p.112). While rightly focusing on value, the framework too narrowly focuses on access without defining opportunity. The Capabilities Approach Framework for e-Participation accounts for Alampay's individual differences by placing the individual ahead of the resources (see Figure 8). The individual then has the opportunity to utilize ICTs and ICI which includes e-Government services as well as civic technologies and third party applications such as social media to interact with government within the governance process. Whether e-Participation and e-Democracy takes place is dependent upon the government's ability to facilitate the core set of capabilities necessary to 
convert ICT resources and services into value, intrinsic as well as instrumental. For this reason, the capability set is positioned inside the governance process and the responsibility of the government and it's actors to provide policies and programs that cultivate citizen's existential capabilities beyond access alone.

Figure 8: Capabilities Approach Framework for E-Participation (source: author)

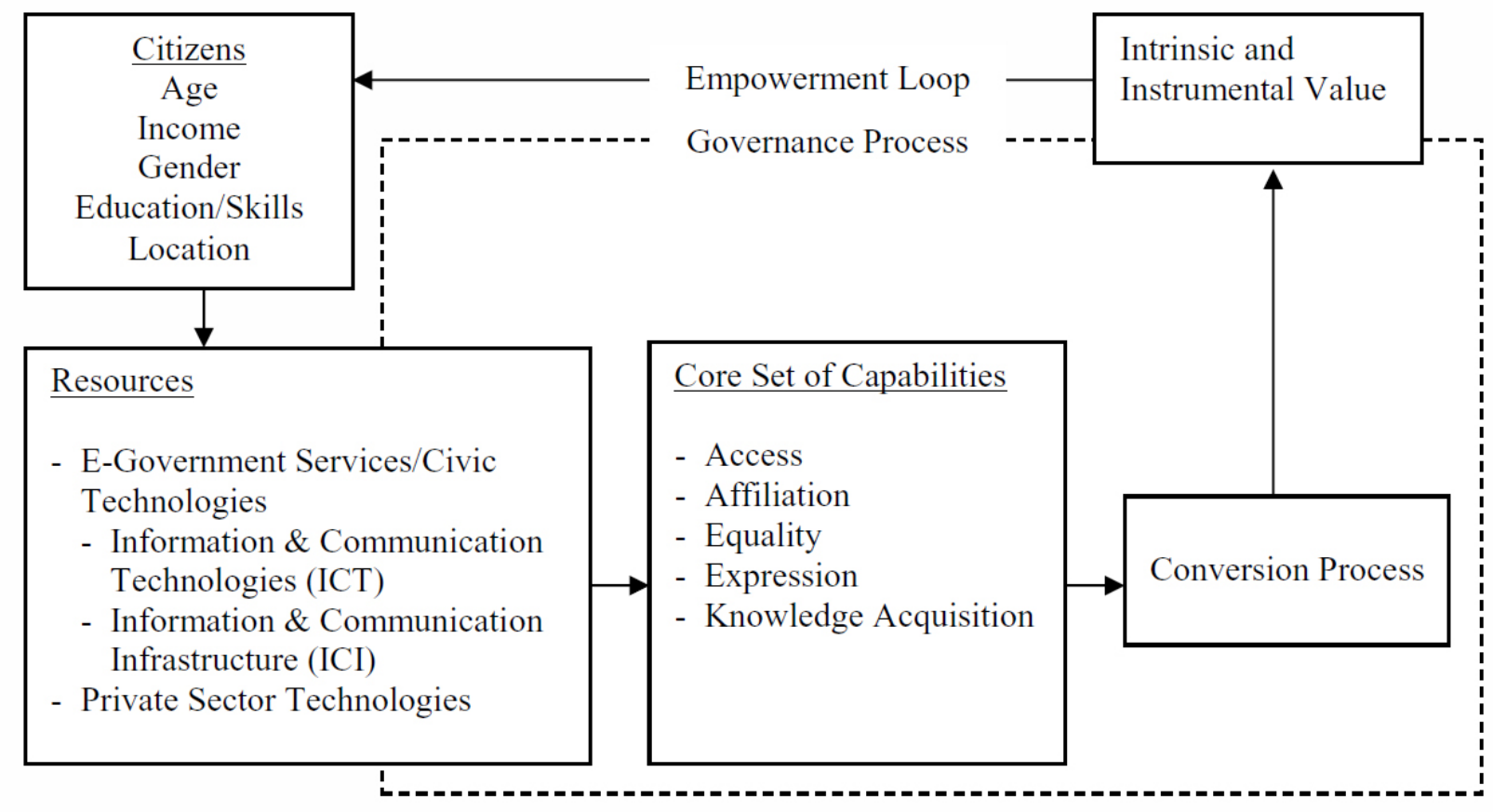

Once citizens are provided with the resources and services, the next step is to convert those resources into valued functionings. This is called the conversion process and where real freedoms are distinguished from paper ones. The conversion process itself is similar to Easton's political system or 'black box' where demands and supports are regarded as inputs, but are instead converted into valued fuctionings for the Government and for the citizens they serve. This is accomplished through participatory governance, which in turn outputs ordnances and policies that are generated through e-Participatory activities. Unlike Easton's Systems Theory, the individual and the environment are symbiotically ingrained into the governance process. Although the modality of this framework is specific to the Philippines, the normative set of capabilities can be tailored to each country. The next logical step would be to do cross-county comparisons, which could ultimately lead to the operationalization of this approach. In order to do so, it would be imperative to produce meta-rankings for each capability or some other form of evaluative measurement, which is outside the scope of this research. As a final component, the framework provides a feedback loop, much like Easton's approach. In this case, the feedback loop has an empowerment effect on the well-being of the participant also known as the empowerment loop as described by Nath. This also reinforces the notion that the core set of capabilities should be sustainable.

This more existential approach for promoting e-Participation and social inclusion in the governance process better reflects the capabilities necessary for citizens to achieve value through 
civic engagement. This in turn provides benefits to citizens as well as to the government, whereby strengthening the state through a deepening of democracy. Furthermore, this framework may assist policy makers and practitioners looking to implement socially inclusive e-Government programs and initiatives.

\section{Conclusion}

This study has shown that access approach models for e-Participation have been strong drivers for socially inclusive governance but have left many citizens out of the governance process. Moreover to meet the targets outlined in the 2030 Agenda for Sustainable Development, governments will need to focus their attention on the existential capabilities affecting citizen's opportunities to achieve value through e-Participation. While many scholars and institutions have touted the potential benefits for improving governance through e-Participation, the actual results are mixed. Web 2.0 technologies such as Facebook has proven to be a strong civic technology for fostering eDemocracy through responsive, inclusive and representative decision make; however eGovernment initiatives such as TVWS and Tech4ED in the Philippines have fallen into the trap of enhancing ICTs and e-Government services rather than on expanding opportunities and encouraging citizens to participate. To overcome these barriers policies need to be implemented that focus on cultivating the core set of capabilities presented in this article. By doing so, the opportunities for citizens to participate will expand whereby allowing citizens to convert eGovernment services into sustainable value. The results can empower citizens and potentially transform the political landscape through e-Participation.

\section{References}

Alampay, E. (2006). Beyond access to ICTs: Measuring capabilities in the information society. International Journal of Education and Development using ICT. 2(3), 4-22.

Backus, M. (2001). E-Governance and Developing Countries: Introduction and Examples. Research Report No. 3, International Institute for Communication and Development.

Blakeley, C. J. and J. H. Matsuura (2001). "E-Government: Is EDemocracy Inevitable?" Alliance Law Group LLC.

Burgess, S. \& Houghton, J. (2006). E-government in Australia. In P.Hernon, R.Cullen, \& H.C. Relyea (Eds.), Comparative perspectives on e-government: Serving today and building for tomorrow (pp. 84-101). Lanham, Maryland: Scarecrow Press Inc.

Cho, I. (2008). Digital Democracy and Citizenship as the Democratic Political Systems for the Information Age.

Coleman, S., \& Norris, D. F., (2005), A new agenda for e-democracy, Oxford Internet Institute, Forum Discussion Paper No. 4

Clift, S. (2004). "E-democracy, e-governance and public net-work." Open Source Jahrbuch: 317-329. 
Creswell, J. (2003). Research design qualitative, quantitative, and mixed methods approaches. (2nd ed., pp. 209-215). Thousand Oaks, CA: Sage Publications, Inc.

Datar, M., Panikar A., and Farooqui, J. (2008). Emerging Trends in E-Government. Foundations of Egovernment (pp. 37-46). India: Computer Society of India. Retrieved from http://www.csisigegov.org/critical_pdf/4_37-46.pdf

Easton, D. (1965). A framework for political analysis. Englewood Cliffs, NJ: Prentice-Hall.

Easton, D. (1957). An Approach to the Analysis of Political Systems. World Politics, 383-400, p. 384

Freeman, J. (2013). Local e-government and citizen participation: Case studies from Australia and Italy. In J. R. Gil-Garcia (Ed.), E-Government Success Around the World: Cases, Empirical Studies, and Practical Recommendations (pp.235-258). Hershey, Pennsylvania: IGI Global.

Flamm, K., Chaudhuri, A., \& Associates, (2006). The internet, the government, and e-governance. In P. Hernon, R. Cullen \& H. C. Relyea (Eds.), Comparative Perspectives on E-Government: Serving Today and Building for Tomorrow (pp.331-348). Lanham, Maryland: Scarecrow Press Inc.

Garnham, N. (1997). Amartya Sen's "Capability" Approach to the Evaluation of Welfare: Its Application to Communications. Javnost - The Public, 4(4), 25-34.

Garson, D. G. (2006). Public Information Technology and E-Governance: Governing the Virtual State. Public Administration, Vol. 85, No. 3, 2007, p. 857-860.

Hague, B. N., \& Loader, B. D. (Eds.) (1999). Digital Democracy: Discourse and Decision Making in the Information Age.London: Routledge.

Heeks, R. \& Bailur, S. (2007). Analyzing e-government research: Perspectives, philosophies, theories, methods, and practice. Government Information Quarterly, 24(2), 243-265.

Hernon, P., \& Cullen, R. (2006). E-government: Transforming government. In P. Hernon, R. Cullen \& H. C. Relyea (Eds.), Comparative Perspectives on E-Government: Serving Today and Building for Tomorrow (pp. 3-21). Lanham, Maryland: Scarecrow Press Inc.

Huffman, B. (2002). "Building a Wireless Bridge over the Digital Divide" UNCRD, Regional Development Dialogue, 23(2): 137-154ITU (2003). World telecommunication development report: 2003. Geneva.

Jimenez, B. S., Mossberger, K., \& Wu, Y. (2012). Municipal Government and the Interactive Web: Trends and Issues for Civic Engagement. In A. Manoharan \& M. Holzer (Eds.), E-Governance and Civic Engagement: Factors and Determinants of E-Democracy (pp. 251-271). Hershey, Pennsylvania: IGI Global.

Kardan, A. A. and A. Sadeghiani (2011). "Is e-government a way to e-democracy? A longitudinal study of the Iranian situation." Government Information Quarterly 28(4): 466-473.

Labelle, R. (2005). ICT policy formulation and e-Strategy development: A comprehensive guidebook. UNDPAPDIP ICT4D Series. Elsevier.

Lee, Chung-pin, Chang, Kaiju and Frances, Berry S., (2011). "Testing the Development and Diffusion of EGovernment and E-Democracy: A Global Perspective". Public Administration Review. 
Lester, L., \& Hutchins, B. (2012). The power of the unseen: Environmental conflict, the media and invisibility. Media, Culture \& Society, 34(7), 847-863.

Macintosh, A. (2004). Characterizing e-Participation in policy-making, In the Proceedings of the ThirtySeventh Annual Hawaii International Conference on System Sciences (HICSS-37), January 5 - 8, 2004, Big Island, Hawaii., CiteSeerX: 10.1.1.98.6150

Moon, M. J. (2002). The evolution of e-government among municipalities: Rhetoric or reality? Public Administration Review,62(4), 424-433.

Mossberger, K., Tolbert, C. J., \& McNeal, R. S. (2008). Digital Citizenship: The Internet, Society, and Participation. Cambridge, Massachusetts: The MIT Press.

Nath, V. (2003). Digital Governance Models: moving towards good governance in developing countries. Innovation Journal, 8(1). Retrieved from http://www.innovation.cc/volumes-issues/nath-digital.pdf

Nussbaum, M. (2000), Women and Human Development: the Capabilities Approach, Cambridge: Cambridge University Press.

Nussbaum, M (2011). Creating Capabilities: The Human Development Approach. Cambridge, MA: Harvard University Press. pp. 33-34. ISBN 0674072359.

O'Toole, K. (2009). Australia local government and e-governance: From administration to participation? In M. Khosrow-Pour (Ed.), E-Government Diffusion, Policy, and Impact: Advanced Issues and Practices (pp. 174-184). Hershey, Pennsylvania: IGI Global.

Robeyns, I. (2003). Sen's Capability Approach and Gender Inequality: Selecting Relevant Capabilities.Feminist Economics, 9(2-3), 61-92.

Sen, A. (1985), “Well-being, Agency and Freedom: The Dewey Lectures 1984,” Journal of Philosophy, 82(4): 169-221.

Sen, A. (1992). Inequality reexamined. New York Oxford New York: Russell Sage Foundation Clarendon Press Oxford Univ. Press. ISBN 9780198289289.

Thompson, J. B. (2005). The new visibility. Theory, Culture \& Society, 22(6), 31-51.

UN (United Nations). (2016). United Nations E-Government Surveys 2016: E-Government in Support of Sustainable Development. New York: United Nations. ISBN: 978-92-1-123205-9

UNPAN (United Nations Public Administration Program). (2005). Global E-Government Development Report 2005 - From E-government to E-inclusion. New York: United Nations. UNPAN/2005/14

Verdegem, P., \& Hauttekeete, L. (2010). A user-centric approach in e-government policies: The path to effectiveness? In. C.G. Reddick (Ed.), Citizens and E-Government: Evaluating Policy and Management (pp. 20-36). Hershey, Pennsylvania: IGI Global.

Yin, R. (2003). Case study research design and methods. (3rd ed., Vol. 5). Thousand Oaks, CA: Sage Publications, Inc. 


\section{About the Author}

\section{Benjamin D Huffman}

He is a fourth year doctoral student at Nagoya University's Graduate School of International Development, Governance \& Law Program. Prior to joining Nagoya University, he worked as an ICT consultant for the World Bank and as an ICT research assistant for the United Nations Centre for Regional Development (UNCRD). He also spent six years in local government working as an e-Government practitioner implementing various projects in the field of public safety services. 